\title{
Erratum to: Effect of the addition of nano-sized sodium hexametaphosphate to fluoride toothpastes on tooth demineralization: an in vitro study
}

\author{
Giovanna Dalpasquale $^{1}$ - Alberto Carlos Botazzo Delbem ${ }^{1}$ • Juliano Pelim Pessan ${ }^{1}$. \\ Gabriel Pereira Nunes ${ }^{1} \cdot$ Luiz Fernando Gorup ${ }^{2}$ - Francisco Nunes Souza Neto ${ }^{2}$. \\ Emerson Rodrigues de Camargo ${ }^{2} \cdot$ Marcelle Danelon $^{1}$
}

Published online: 18 April 2017

(C) Springer-Verlag Berlin Heidelberg 2017

\section{Erratum to: Clinical Oral Investigations}

DOI 10.1007/s00784-017-2093-3

There was a mistake in the Conflict of interest and Funding statements of the original published article. Correct statements are provided here.

Conflict of interest The authors Marcelle Danelon, Alberto Carlos Botazzo Delbem, Juliano Pelim Pessan and Emerson Rodrigues de Camargo hold a patent request for a product used in the study, by the National Institute of Industrial Property - INPI / SP, on 10/17 / 2014 under number BR 10 20140259023 . All authors approved the publishing of the manuscript.

Funding This study was funded by the CAPES, FAPESP (scholarships to the first and fourth authors, respectively) and CNPq/PQ (Process. n. 308981/2014-6) to the second author.

Marcelle Danelon

marcelledanelon@hotmail.com

1 Department of Pediatric Dentistry and Public Health, São Paulo State, University (Unesp), School of Dentistry, Rua José Bonifácio 1193, Araçatuba, São Paulo 16015-050, Brazil

2 LIEC-Department of Chemistry, Federal University of São Carlos, (UFSCar), Rodovia Washington Luís, São Carlos, São

Paulo 13565-905, Brazil 